\title{
Shoulder Tip Pain in Laparoscopic Cholecystectomy with Active vs Passive Evacuation of Pneumoperitoneum
}

\section{Anum Arif, ${ }^{1}$ Sabih Nofal, ${ }^{2}$ Muhammad Atif Khan, ${ }^{3}$ Abdul Waheed Khan, ${ }^{4}$ Ahsin M Bhatti, ${ }^{5}$ Syed Haider Ishaq $^{6}$}

\begin{abstract}
Objective: The objective of the study was to compare the frequency of severity of shoulder tip pain after active (gas suctioning) and passive removal of pneumoperitoneum among patient undergoing laparoscopic cholecystectomy.

Methods: This Observational comparative study was directed in general surgery department of DOW university hospital beginning from February 2016 to February 2017. Two hundred and six patients undergoing standard 4 port laparoscopic cholecystectomy were enrolled equally in either groups. The surgeon evacuated the abdomen by using a multiporous suction tube limiting the negative suction pressure to - $40 \mathrm{mmHg}$ for 2-5 minutes under direct vision in active aspiration group, while in control group, $\mathrm{CO}_{2}$ was removed passively. Pain scores were recorded using visual analog score at 16 hours post-operatively by residents of surgery blinded to the study.
\end{abstract}

Results: Mean VAS pain score at 16 hours in intervention group was much inferior than control group 1.00 \pm 2.09 vs. $3.06 \pm 2.58(\mathrm{p}<0.001)$.

Conclusion: Active aspiration of $\mathrm{CO} 2$ is an effective method that removes most if not all gas from the abdominal cavity. This will cause statistically significant decrease post-operative discomfort, pain and decrease need of rescue analgesics.

Key Words: Laparoscopic cholecystectomy, Pneumoperitoneum, Active Aspiration, shoulder tip pain, postlaproscopic cholecystectomy pain

How to Cite: Arif A, Nofal S, Khan MA, Khan AW, Bhatti AM, Ishaq SH. Shoulder tip pain in laparoscopic cholecystectomy with active vs passive evacuation of pneumoperitoneum. Esculapio. 2020;16(04):116-119.

DOI: https://doi.org/10.51273/esc20.2516425

\section{Introduction}

$\mathrm{L}$ aparoscopic cholecystectomy has largely replaced conventional open cholecystectomy. ${ }^{1}$ It provides great satisfaction to patient and at the same time beneficial for the operating surgeon as well in terms of high grade visibility minimum operative time,

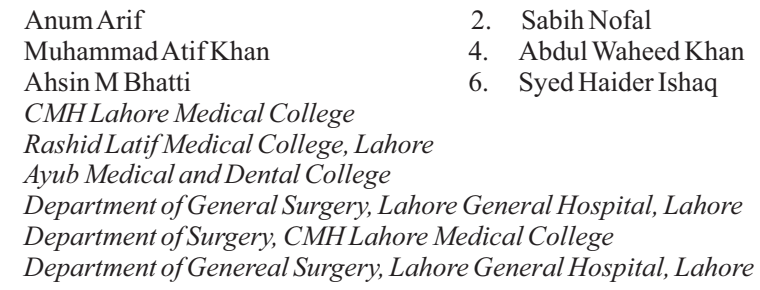

2. Sabih Nofal

4. Abdul Waheed Khan

6. Syed Haider Ishaq

Dr. Sabih Nofal, Consultant General and Laparoscopic Surgeon. Fellow Vascular Surgery, CMH Rawalpindi Medical College,

E-mail:drsabih@gmail.com

Submission Date:

1st Revision Date:

Acceptance Date:

hore


phrenic nerve irritation. ${ }^{2}$ Therefore reduction in post laparoscopic cholecystectomy pain can be done by multiple methods like low pressure pneumoperitoneum, instillation of NSAIDS, instillation of intraperitoneal local anesthesia, infiltration of wound with local anesthesia and removal of residual pneumoperitoneum. ${ }^{3,5,6,7}$ Various methods have been introduced like pulmonary recruitment maneuver consisting of two to five insufflations, at the end of procedure active suctioning of $\mathrm{CO}_{2}$ or filling the abdomen with warm saline. ${ }^{1,4,8}$ Patient receiving abdominal filling with saline voided noticeable amount of urine following the immediate post-operativenight, disposes the patient to fluid overload and its time consuming., Pulmonary recruitment maneuvers carries risk of pneumothorax and increased morbidity. ${ }^{12}$ It implies that none is proven to be as assuring to be a standard method. Since no local data is available, and there is no standard technique, the rationale of the study was to see the effect of active aspiration of $\mathrm{CO}_{2}$ as a superior technique. The objective of the study was to compare the frequency of severity of shoulder tip pain after active (gas suctioning) and passive removal of pneumoperi-toneum among patient undergoing laparoscopic cholecystectomy.

\section{Methods}

This observational comparitive study was performed in general surgery department, DOW university hospital, from February 2016 to February 2017 over a period of one year after approval from research and training cell of CPSP. A total of 216 patients of either gender, age ranged between 20 to 60 years and undergoing interval laproscopic cholecystectomy were included in the study. Pregnant females, HTN, COPD and DM, laparoscopic cholecystectomy converted to open cholecystectomy, ended in common bile exploration and Placement of drains were excluded. The Rao soft software was used for "sample size calculaton|. Proportion of the incidence of shoulder pain varies from $35 \%$ to $80 \%$ and ranges from mild to severe with confidential interval of $95 \%$ and margin of error of $9 \%$ sample size was $n=108$ in each group. ${ }^{4}$ All patients undergoing standard 4 port laparoscopic cholecystectomy were recruited in either of the 2 groups. Intervention group was labelled as group A and control group as group B. In Group A, the surgeon evacuated the abdomen by using a multiporous suction tube limiting the negative suction pressure to -40
$\mathrm{mmHg}$ for 2-5 minutes under direct camera view, while in group $\mathrm{B}, \mathrm{CO}_{2}$ was removed passively, trocars were removed and incisions were closed. Pain scores were recorded using visual analog score at 16 hours post operatively by residents of surgery blinded to the study Those patients, who experience moderate to severe pain in spite of routine analgesics received a single bolus dose of Diclofenac sodium $75 \mathrm{mg}$ intramuscular or injection Nalbuphine $5 \mathrm{mg}$ intravenous maximum thrice in 24 hours if needed.

Statistical package of social science software, SPSS, version 16 was used for data analysis. Frequency and percentage quantitative variables and mean and SD of qualitative variables was calculated. To compare both groups, the chi-square test was used. P value of $\leq 0.05$ was considered statistically significant.

\section{Result}

The study is based on total of 216 patients and none of them were excluded. Out of them, 108 were allocated I neither group by sealed envelod method. Demographic variables are mentioned in table 1.

It was observed that 107 (91.1\% ) patients in control and $28(25.9 \%)$ patients in case developed pain. $\mathrm{P}$ value $<0.001$ for both groups.

The pain intensity was further characterized as no pain, mild moderate and severe pain based on Visual Analog Scale from 0 to 10. The results are as shown in graph 1. Over all Mean VAS score at 16 hours after laparoscopic cholecystectomy was $2.03 \pm 2.56$. The score in control group which was much higher than case group (3.06 \pm 2.58 vs. $1.00 \pm 2.09)$.

After stratification in the context of effect modifiers, age, height, weight, BMI and period of surgery, it was found that all of them effect pain outcome. However it was observed that in age group between 20 - 30 years, no significant association was found with pain score ( $p$ value 0.77 ). Severity of pain score had significant association with age and BMI ( $p$ value $<0.001$ ). However, BMI of range between $20-25 \mathrm{~kg} / \mathrm{m}^{2}$ had no association with the severity of pain ( $p$ value 0.438 ).

\section{Discussion}

Pain after laparoscopic surgery can occur in abdomen, either upper or lower, back or either shoulders. ${ }^{10-12}$ It can be transient or lasting up to days. ${ }^{10}$

Shoulder tip pain was documented in $99.07 \%$ of the control group and $32.85 \%$ of case group in our study. This shows that over all pain score in case group was 
Table 1: Description of Patient's Characteristics $(n=216)$

\begin{tabular}{|c|c|c|c|}
\hline CHARACTERISTICS & CONTROL & CASE & P value \\
\hline & n 108(\%) & n $108(\%)$ & \\
\hline \multicolumn{4}{|l|}{ AGE GROUPS } \\
\hline $20-30$ & $72(66.7)$ & $12(11.1)$ & $<0.001$ \\
\hline $31-40$ & $18(16.7)$ & $31(28.7)$ & \\
\hline $41-50$ & $18(16.7)$ & $65(60.2)$ & \\
\hline \multicolumn{4}{|l|}{ SEX } \\
\hline Male & $48(44.4)$ & $17(15.7)$ & $<0.001$ \\
\hline Female & $60(55.6)$ & $91(84.3)$ & \\
\hline \multicolumn{4}{|l|}{ BMI } \\
\hline $20-25$ & 61 & 31 & \\
\hline $25-30$ & 41 & 22 & $<0.001$ \\
\hline $35-40$ & 6 & 55 & \\
\hline \multicolumn{4}{|l|}{ DURATION OF SURGERY } \\
\hline$<30 \operatorname{mins}$ & 0 & $6(5.6)$ & \\
\hline $30-60$ mins & $54(50 \%)$ & $41(38)$ & $<0.001$ \\
\hline $61-120$ mins & $54(50 \%)$ & $9(8.3)$ & \\
\hline$>121$ mins & 0 & $52(52)$ & \\
\hline
\end{tabular}

Table 2: Description Of Analgesic Requirement $N=31$

\begin{tabular}{cccc}
\hline CHARACTERISTICS & $\begin{array}{c}\text { CONTROL } \\
\text { n(\%) }\end{array}$ & $\begin{array}{c}\text { CASE } \\
\text { n(\%) }\end{array}$ & $\begin{array}{c}\text { P- } \\
\text { value }\end{array}$ \\
\hline ADDITIONAL ANALGESICS NAMES \\
Toradol & $18(58)$ & $13(41.9)$ & $<0.01$ \\
Toradol and Nalbuphine & $18(58)$ & $2(6.4)$ & \\
ADDITIONAL ANALGESICS FREQUENCY & \\
Once & $18(58)$ & $13(41.9)$ & $<0.01$ \\
multiple & $18(58)$ & $2(6.4)$ & \\
\hline
\end{tabular}

significantly lower ( $p$ value $<0.001)$.

Similar study conducted by Jasmin et al showed no pain $86.2 \%$ in the case group. ${ }^{4}$ The results are comparable with our study in which $78.8 \%$ of intervention group had no pain. In another research done by Fredman B et al., the active aspiration (AA) group in which gas was actively aspirated by suction, while no efforts, in the non-active aspiration (NAA) group, were made. ${ }^{13}$ Throughout the initial post-operative hour, lesser stresses were made by AA patients for morphine in comparison to those who belong to NAA group $(15.3 \pm 15.7$ vs $31.3 \pm 26.2)$ and also obtained a smaller dose of PCA morphine $(2.7 \pm 1.3 \mathrm{mg}$ vs $3.9 \pm 1.9 \mathrm{mg}) \mathrm{P}=0.056$. This concluded that residual pneumoperitoneum was one of the important contributing factor leading postoperative pain as shown in previous studies in literatrure. ${ }^{13,14}$

In a recent international study, patients experiencing mild, moderate and severe pain were $15.5 \%, 49.3 \%$ and $35.2 \%$ from control group and $13.8 \%$ from intervention group experienced mild pain. However, none of the patient experienced moderate and severe pain. ${ }^{4}$ Whereas in our study, $7.4 \%$ of Group A patient had mild pain whereas $12 \%$ and $1.9 \%$ patients moderate and severe pain. One of the explanations can be difference of suction pressure used in either studies. It can be concluded to question the efficiency of various proposed method and some more trials should be conducted to decide which is the suitable one.

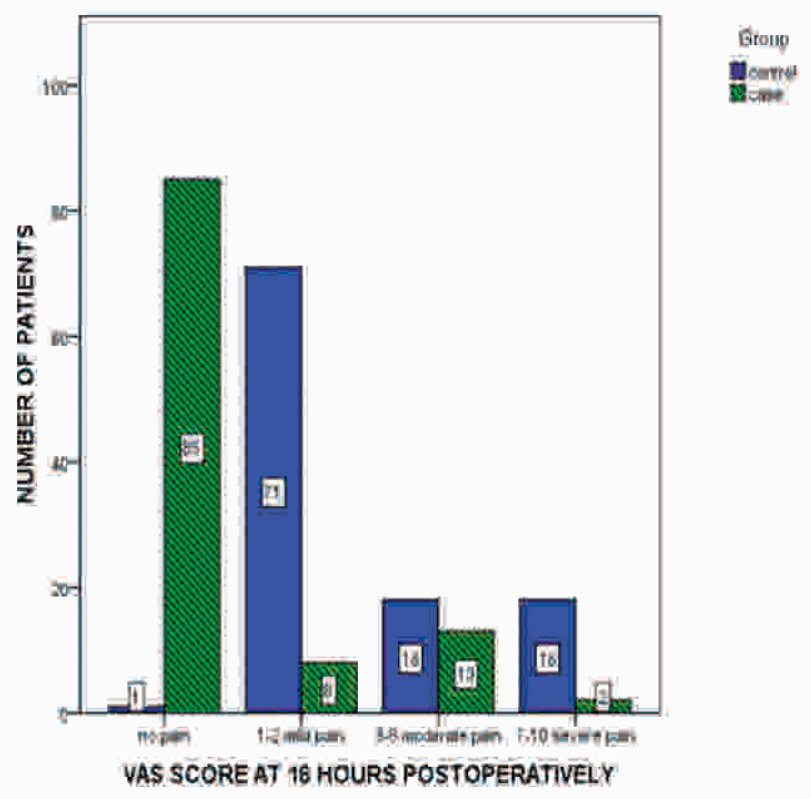

Figure 1: Stratification According to Pain and Severity of Pain

Results of our study are comparable with study conducted by Jasmin $\mathrm{S}$ et al. in which rescue analgesia was required by $33.1 \%$ of the study population in contrast to only $14.3 \%$ in our present study. ${ }^{4}$ Out of these, in contrast, their requirement of analgesia by control and case group were $50 \%$ and $42.3 \%$ which was significantly higher than our study. ${ }^{4,15}$ This brights to highlight that patient's decrease demand of additional analgesia is an indirect measure of our maneour to evacuate pneumoperitomeum. Since no local data is available in our country, we do not have any standard guidelines for our population. The limitation f our study was a single center study with small sample size. Further studies are required so that a concerte guideline can be postulated and new standards of care can be postulated for the best intrest of patient.

\section{Conclusion}

Active aspiration of $\mathrm{CO}_{2}$ is an effective method that removes most if not all gas from the abdominal cavity. This will cause statistically significant decrease postoperative discomfort, pain and decrease need of rescue analgesics 


\section{Conflict of Interest: $\quad$ None}

\section{References}

1. Khanna A, Sezen E, Barlow A, Rayt H, Finch JG. Randomized clinical trial of a simple pulmonary recruitment maneuver to reduce pain after laparoscopy. Br J Surg. $2013 ; 100: 1290-1294$.

2. Sarvestani AS, Zamiri M. Residual pneumoperitoneum volume and post laparoscopic pain. Anesth pain med. $2014 ; 4(4)$ :e17366.

3. Suginami R, Taniguchi F, Suginami H. Prevention of post laparoscopic shoulder pain by forced evacuation of residual CO2 .JSLS. 2009;13:56-59.

4. Salman JM, Merdan I, AsfarSN. The efficacy of active gas suctioning to decrease the residual $\mathrm{CO}_{2}$ for preventing post laparoscopic cholecystectomy shoulder pain. Bas J Surg. 2012;18:1-10.

5. Luketina RR, Knauer M, Kohler G, Koch OO, Strasser K, Egger M. Comparison of a standard $\mathrm{CO}_{2}$ pressure pneumoperitoneum insufflators versus air seal study protocol of a randomized controlled trial. Trials 2014;15:239.

6. Singla S, Mittal G, Raghav, Mittal RK. Pain management after laparoscopic cholecystectomy-a randomized prospective trial of low pressure and standard pressure pneumoperitoneum. Journal of clinical and diagnostic research. 2014;8(2):92-94.

7. Shin HY, Kim SH, Lee YJ ,Kim DK, .The effect of mechanical ventilation tidal volume during pneumoperitoneum on shoulder pain after a laparoscopic appendectomy. Surgendose. 2010;24:2002-2007.

8. Phleps P, Cakmankkaya S, Apfel CC, Radke OC. A simple clinical maneuver to reduce laparoscopyinduced shoulder pain a randomized control trial. Obstet gynecol. 2008;111:1155-1160.

9. TsaiHW, Chen YJ, Ho C M, Hseu SS, Chao KC, Tsai SK et al. Maneuvers to decrease laparoscopy-induced shoulder and upper abdominal pain a randomized control trial. Arch surg. 2011;146 (12):1360-1366
10. Alexander J. I. Pain after laparoscopy. Br. J. Anaesth. 1997;79:369-378.

11. Sattar Z, Kareem Ullah M, Ahmed MS, Bashir S, Chaudhry SM, Zahid I M. Outcome comparison in patients undergoing laparoscopic cholecystectomy using low pressure and standard pressure pneumiperitoneum. PJHMS. 2015:1(9);77-79.

12. Siddiqui NA, Azami R, Murtaza G, Nasim S. Post operative port-site pain after gall bladder retrieval from epigastric vs. umblical port in laparoscopic cholecystectomy: A randomized control trial. International Journal of Surgery. 2012;213-216.

13. Fredman B, Jedeikin R, Olsfanger D, Flor P, Gruzman A. Residual pneumoperitoneum: a cause of postoperative pain after laparoscopic cholecystectomy. AnesthAnalg. 1994;79(1):152-154.

14. CouceiroTC, Valença MM, Lima LC, de Menezes TC, Raposo MC. Prevalence and influence of gender, age, and type of surgery on postoperative pain. Rev Bras Anestesiol. 2009;59(3):314-320.

15. Sarli L, Costi R, Sansebastiano G, Trivelli M, Roncoroni L. Prospective randomized trial of lowpressure pneumoperitoneum for reduction of shoulder-tip pain following laparoscopy. Br J Surg. 2000; 87(9):1161-1165.

16. Perrakis E, Vezakis A, Velimezis G, Savanis G, Deverakis S, Antoniades J et al. Randomized comparison between different insufflation pressures for laparoscopic cholecystectomy. SurgLaparosc Endosc Percutan Tech. 2003;13(4):245-249.

\section{Author's Contribution}

AA: Manuscript writing \& data collection

NS: Manuscript writing \& data processing

KAM: Data collection

KWA: Proof reading \& correction

BMA: Proof reading \& supervision

IHS: Data collection 